\title{
Study on the Influence of Blade Roughnesson Axial Flow Compressor Stage Performance
}

\author{
Xudong Shi ${ }^{1}$, Hui Liư ${ }^{2}$, Feiqi Long ${ }^{1}$, Jie Tang ${ }^{3}$ and Liwen Wang ${ }^{4}$ \\ ${ }^{1}$ Electronic Information and Automation College, Civil Aviation University of China, China \\ ${ }^{2}$ Sino-European Institute of Aviation Engineering, Civil Aviation University of China, China \\ ${ }^{3}$ Mechanical Engineering Department, Civil Aviation University of China, China \\ ${ }^{4}$ Aviation Ground Special Equipments Research Base, Civil Aviation University of China, China
}

\begin{abstract}
A typically actual inlet stage NASA Stage 36 is chosen to study the influence of surface roughness on axial compressor performance. Firstly, a geometry model is created by blade design software BladeGen using transferred coordinates data of blade profile and flow path. Secondly, validation of simulation model is conducted by comparing computational data and field experiment data. Lastly, SST k- $\omega$ turbulence model is chosen to study the influence of blade surface roughness on performance parameters under different work points. It shows that adding roughness will significantly reduce axial compressor stage's adiabatic efficiency and total pressure ratio and cause stage characteristic map shift toward left. It should not neglect the influence of surface roughness of stator near stall region under $100 \%$ design speed; Mach number shows a big difference after adding surface roughness, and it can be considered as a sensibility parameter of roughness.
\end{abstract}

\section{Introduction}

The performance deterioration of compressor is directly connected to aircraft safety and efficiency, it has become more and more important to study the factors causing compressor performance deterioration and to explore the laws of performance deterioration. Blade damages like fouling, missing material or coating and tip curl change blade profile parameters and surface characteristics, the latter mainly acts as the increase of surface roughness, among which fouling is the main factor.

The roughness correction of turbulence flow dates back to the study of pipe flow conducted by Nikuradse [1] in 1933. From the view of boundary layer development, he discovered that it can be divided into three regimes to study the influence of roughness on pipe flow according to Reynold number value, pipe pressure loss coefficient depends on Reynold number and roughness height under low Reynold number condition, whereas friction resistance of pipe wall depends only on sand-grain diameter under high Reynold number condition. Schilichting [2] used Nikuradse's experiment data to correlate different rough surface types by which he came up with the concept of 'equivalent sand-grain roughness', which provided a method to describe randomly rough surface by an 'equivalent' uniform layer of actual sandgrain diameter, and his this methodology has gained a worldwide acceptance.

There is no doubt that roughness has a big influence on compressor performance as it changes the flow condition in compressor. Bammer [3] experimentally obtained the changes about the pressure distribution around blade profile, the boundary-layer development along profile contour, and the velocity distribution in the boundary layer due to increasing roughness on NACA 65-series compressor blade sections of different geometrical sizes. Syverud et al. [4-5] presented the deterioration of overall engine performance caused by spraying atomized droplets of saltwater into the axial compressor of engine GE J85-13, based on those test data, they also studied the influence of roughness on compressor performance from the perspective of friction loss, blockage and airflow separation, it shows that the most significant effect of salt deterioration is the reduction in flow coefficient. In order to study the influence of adding blade thickness and roughness on performance, Suder et al. [6] applied rough coatings to the pressure and suction surface of rotor blades, the results shows that roughness has the most significant influence on performance near the design point. Based on k- turbulence model, Mirko Morini et al. [7] chose NASA Stage 37 to study fouling influence on performance deterioration and flow blockage, according to their research, reductions in the flow coefficient and in the pressure coefficient were found to be the same order of magnitude of experimental results. Also based on kturbulence model, Shi Hui et al. [8-9] chose NASA Stage 35 to study the influence of adding thickness and roughness caused by fouling on compressor stage performance, and it shows that the influence of roughness applied on rotor is nearly the same as that on whole stage. With the same method, Rotor 37 is chosen to study the 
influence of fouling on compressor performance, an emphasis was putted on studying the relationship between rotor performance and shock wave, shock wave/boundary interaction.

There are already many valuable results in terms of theory, experiment and numerical simulation about how surface roughness affects flow condition. In this paper, the effect of surface roughness on blades of NASA Stage

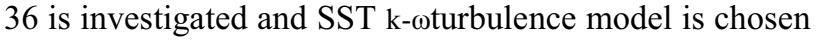
for three-dimensional numerical simulation. The feasibility of numerical model is conducted by comparing numerical results and experiment data. Different levels of surface roughness are considered to study fouling effects on compressor stage performance under different work points, and variations of input power and Mach number are also discussed.

\section{Numerical simulations}

\subsection{Geometrical model}

In order to study the influence of blade surface roughness on compressor stage's aerodynamic performance, a typically actual compressor stage NASA Stage 36 is employed. The profile, flow path, design point parameters and related experiment data are found in literature [10]. NASA Stage 36 is composed of 48 rotors and 62 stators, the aspect ratios for rotor and stator are respectively 1.63 and 1.78 , design rotation speed is $17188.7 \mathrm{rpm}$ with mass flow of $20.188 \mathrm{~kg} / \mathrm{s}$, design tip speed is $455.233 \mathrm{~m} / \mathrm{s}$, stage total pressure ratio is 1.82 and adiabatic efficiency is $82.2 \%$.

The geometrical modelling is briefly described as follows: data files of blade profile contours of different radius are obtained by coordinate transformation. Geometry of flow path is firstly obtained by fitting of discrete points using SolidWorks, then flow path including hub and shroud data file can be obtained by importing the geometry into blade generation software named BladeGen. Finally, we can obtain rotor or stator geometry by importing those three above data files. Fig. 1 shows the geometrical model of Stage 36.

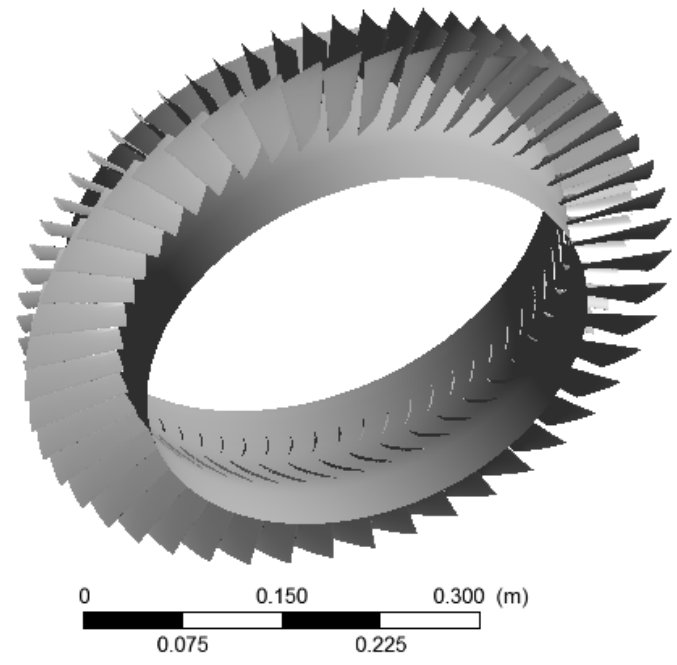

Figure 1. Geometry of NASA Stage 36

\subsection{Turbulence and wall modelling}

Only one passage is computed and the pitch ratio is then 1.29. The meshes were generated in Turbo Grid 14.0, using 'J-Grid' structured mesh for rotor and ' $\mathrm{H} / \mathrm{J} / \mathrm{C} / \mathrm{L}$ Grid' structured mesh for stator both with O-grid near blade wall, tip clearance is not taken into consideration. The total number of mesh elements is approximately 1000,000 , the first mesh height normal to wall is fixed at $20 \mu \mathrm{m}$, and numerical meshes are shown in Fig. 2. The reason for choosing the height of first grid will be discussed later. Final numerical calculations were done using commercial CFD software ANSYS CFX 14.0 whose calculations is based on Finite Volume Method, a second-order high-resolution advection is used in calculations.

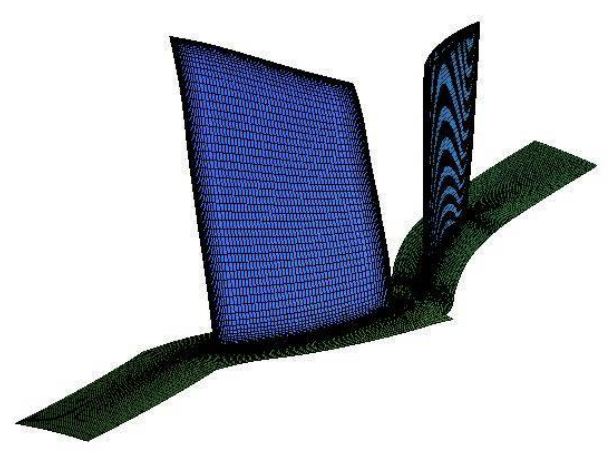

Figure 2. Computational meshes of Stage 36

Surface roughness leads to an increase in turbulence production near the wall, which in turn results in an increase of wall shear stress and breaks up the viscous sublayer of turbulent flow, and it means a downward shift for logarithmic velocity profile. As a result, roughness effects on turbulent flow are realized by changing the logarithmic velocity profile, for ANSYS CFX14.0 [11], it has:

$$
\begin{gathered}
u^{+}=\frac{1}{\kappa} \ln \left(y^{+}\right)+5.2-\Delta B \\
\Delta B=\frac{1}{\kappa} \ln \left(1+0.3 h_{s}^{+}\right) \\
h_{s}^{+}=\frac{h_{s} u_{\tau}}{v}
\end{gathered}
$$

where $u^{+}$is the velocity near the wall, $\Delta B$ is the distance of downward shift of the logarithmic velocity profile, $h_{s}$ is the sand-grain diameter, $u_{\tau}$ is the friction velocity, $v$ is the dynamic viscosity coefficient, $h_{s}^{+}$is a dimensionless sand-grain roughness. Depending on the value of $h_{s}^{+}$, it can divide into three roughness regimes which are hydraulically smooth, transitionally rough and fully rough regimes, which comes to a corresponding relation with the studies of Nikuradse [1] and Schilichting [2].

According to open literatures, k- turbulence model is the most frequently employed model to study the influence of surface roughness on compressor performance, what's more, first mesh height is generally $50 \mu \mathrm{m}$ and maximum roughness value is about $100 \mu \mathrm{m}$ [7-

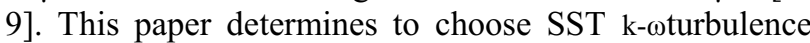
model, which to some degree covers the shortage of model choice. This model is only suitable for small values of $h_{s}^{+}$with automatic rough wall treatment, when a 
roughness height has been specified, then the automatic rough wall treatment is activated. Considering that the first mesh height should be the same order or bigger than the dimensionless sand-grain roughness $h_{s}^{+}$, the first mesh height is chosen as $20 \mu \mathrm{m}$.

\subsection{Boundary condition}

Inlet flow direction is along the rotational axis and inlet total pressure and total temperature are fixed at $101315 \mathrm{~Pa}$ and $288.15 \mathrm{~K}$ respectively. An average static pressure is imposed at outlet, and different work point from nearchoke flow region to near-stall flow regime can be obtained by gradually increasing pressure.

\section{Results and discussion}

\subsection{Model validation}

In Fig. 3, the numerical and experimental performance parameters at $100 \%$ and $70 \%$ design speed are presented. Comparing with the results at $100 \%$ design speed, those at $70 \%$ design speed are better consistent with experimental data, whereas all their mass flows at nearchoke region are bigger than experimental value. There is a good enough agreement of total pressure ratio and adiabatic efficiency between numerical results and experimental results. The reasons for errors include no tip clearance, limited original data of geometry, one-passage calculation, existence of experimental errors and so on. Comparing with NASA Stage 35 and 37, blade number of this stage brings a bigger difficulty in modelling and calculation. Although there were some deviations from experimental results, the numerical results have well reproduced the variation characteristics of compressor stage performance under experiment condition. Therefore, it's feasible to use this model to study the influence of roughness on compressor's aerodynamic performance.

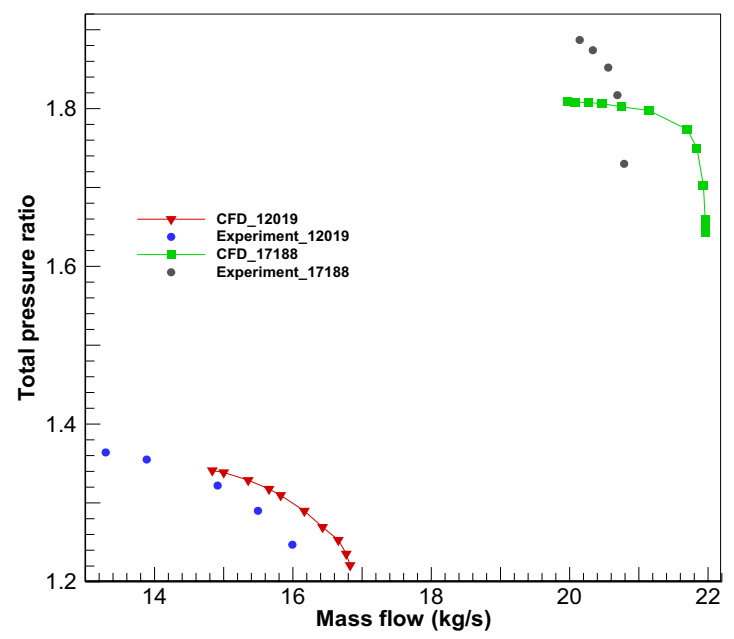

(3.a) Total pressure ratio

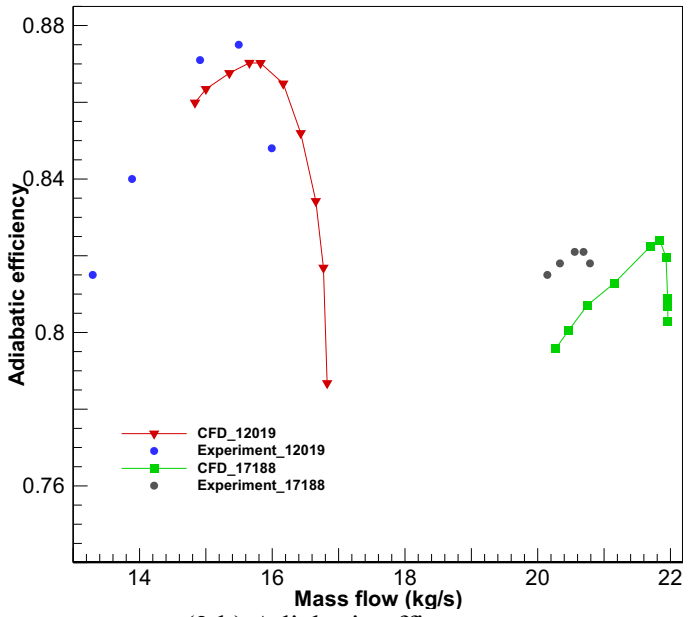

(3.b) Adiabatic efficency

Figure 3. Comparison of characteristic maps between computational and experimental results

\subsection{Stage performance parameters}

In Fig.4, the influences of surface roughness on stage total pressure ratio and adiabatic efficiency at $100 \%$ and $70 \%$ design speed are presented. It can be concluded that the stage performance maps move toward left after adding surface roughness, mass flows in near-choke region and in near-stall region have a remarkable decrease. Total pressure ratio and adiabatic efficiency also decrease, and their decreased magnitudes increase with roughness level and with rotation speed of stage's rotor. At $70 \%$ design speed, the variation of stage performance map has a similar tendency with ones obtained by using k- turbulence model, as the new bladerough performance map has a similarity with the bladeclean performance map. At $100 \%$ design speed, it seems SST k- $\omega$ turbulence model has a stricter treatment for rough wall. Compared with clean blade condition at $100 \%$ design speed and with a same mass flow, there are five percent decrease both for total pressure ratio and adiabatic efficiency when the roughness value is $40 \mu \mathrm{m}$.

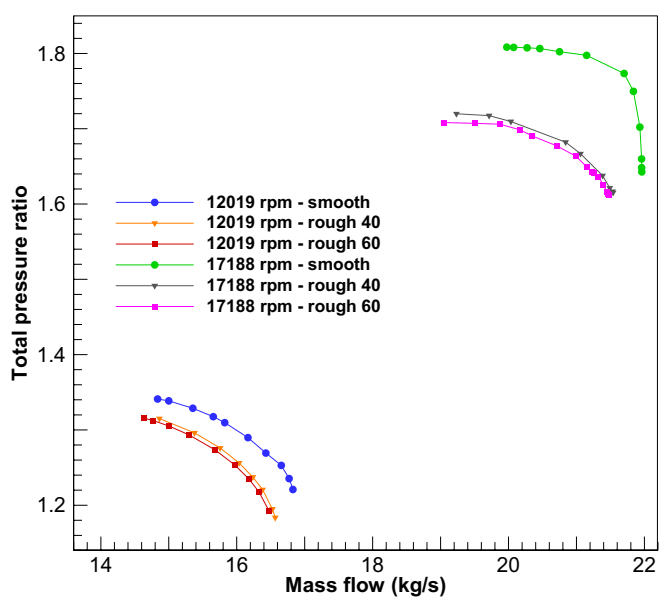

(4.a) Total pressure ratio 


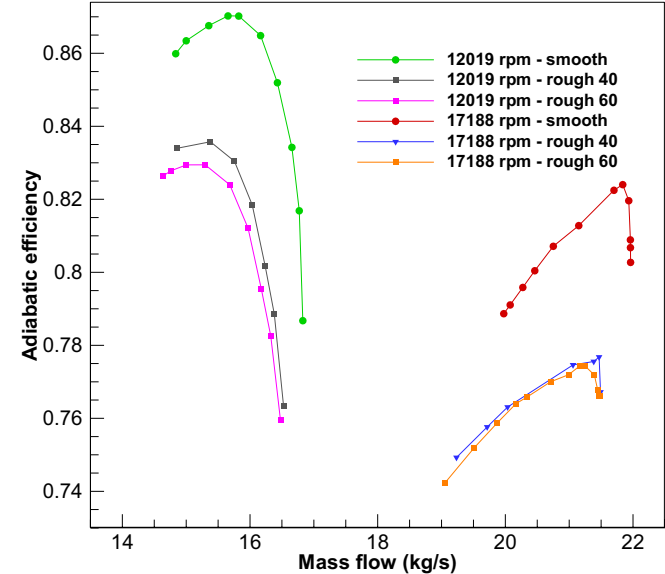

(4.b) Adiabatic efficiency

Figure 4. Effects of surface roughness on stage characteristic maps under different working points

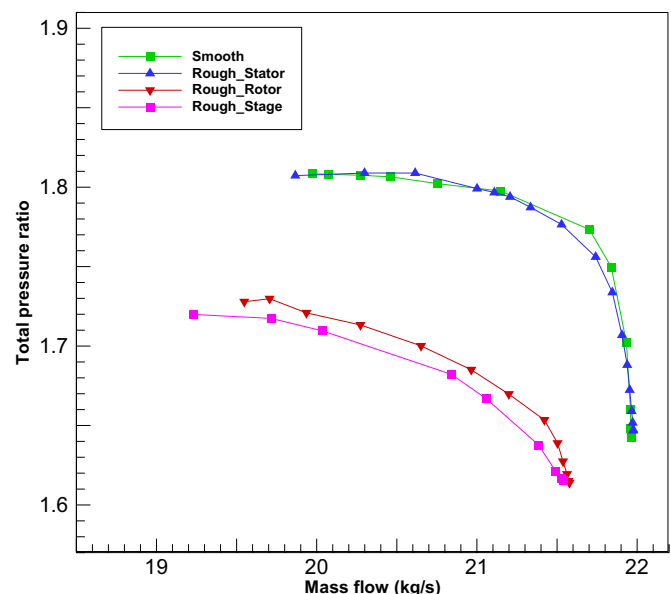

(5.a) Total pressure ratio

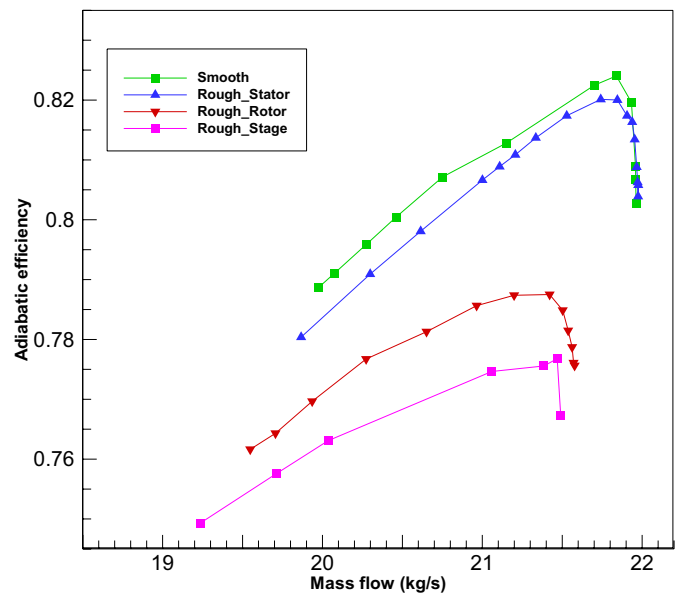

(5.b) Adiabatic efficiency

Figure 5. Sensibilities of rotor and stator to surface roughness at $100 \%$ design speed

In the above case, a same roughness is applied to both rotor and stator. In order to separately consider the influence of roughness on rotor or stator, Fig. 5 shows the variation of stage performance at $100 \%$ design speed when a roughness $40 \mu \mathrm{m}$ is only applied to one of them. It can be concluded: an increase of roughness on stator has nearly no influence on total pressure, mass flow and efficiency in near-choke region, but it has a remarkable effect on adiabatic efficiency in far-choke region; the surface roughness applied to rotor occupies the main impact on stage performance deterioration.

The input powers for smooth blade and blade of roughness $40 \mu \mathrm{m}$ at $100 \%$ design speed are given in Fig.6. For a same pressure ratio, it demands more than $100 \mathrm{~kW}$ more input power for the compressor stage of rough blades; in the near-stall region, roughness causes a decrease of input power of approximately $150 \mathrm{~kW}$. Total pressure ratio gradually increases as mass flow decreases, compared with smooth blade, rough blade aggravates flow separation and therefore impels the compressor to enter near-stall region in advance, which is the reason for an extra input power for a same pressure ratio and an decrease of maximum input power.

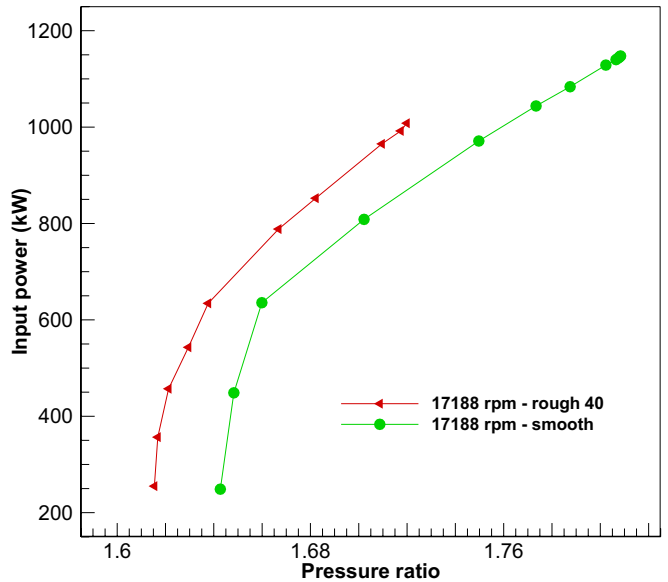

Figure 6. Variation of stage input power along with pressure ratio

\subsection{Mach number}

In near-stall region, the circumferentially averaged relative Mach number at leading edge of rotor along blade span is presented in Fig.7. In this paper, a near-stall point is taken as the work point where it can no longer endure $0.01 \mathrm{~atm}$ static pressure rise on outlet. The circumferentially averaged relative Mach number decreases as blade roughness increase, a significant decrease of relative Mach number happens near 20\% rotor tip.

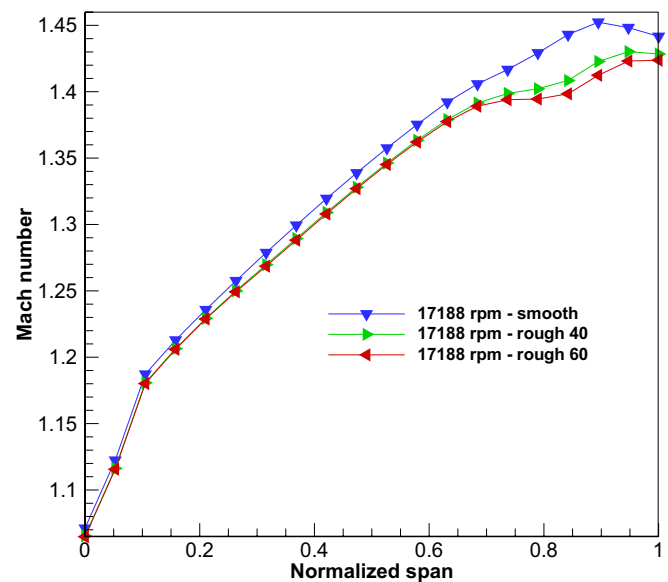

Figure 7. Circumferentially averaged relative Mach number at leading edge 


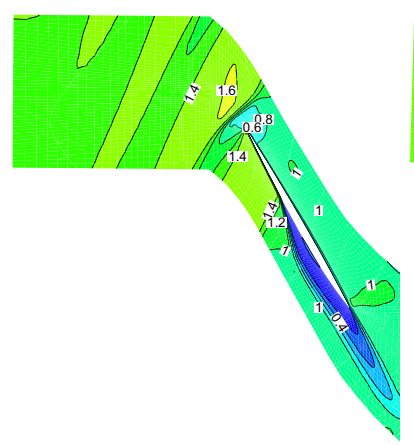

(8.a) Smooth

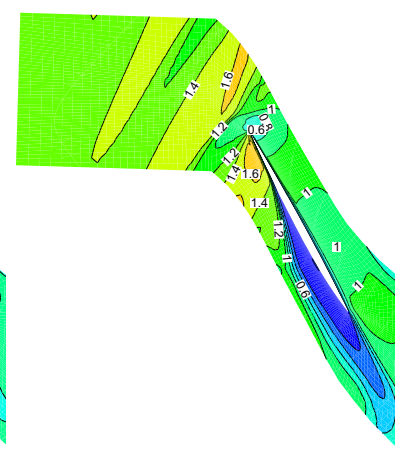

(8.c) $60 \mu \mathrm{m}$

Figure 8. Contour of Mach number at $80 \%$ span

Fig. 8 shows the distribution of Mach number at $80 \%$ span of rotor for near-stall point at $100 \%$ design speed. It can be included that roughness level has a big impact on the distribution of Mach number. Difference mainly manifests as an apparent increase of Mach number near leading edge on suction surface. What's more, the shock wave in the rear of suction surface moves both toward the front and far from blade wall, which will expand wake range of suction surface, create more choked region and further leads to an earlier stall occurrence. The variation of Mach number on pressure surface side is relatively not apparent in all three cases. Combined all analysis above about Mach number, it seems that Mach number is sensitive to surface roughness.

\section{Conclusions}

A geometrical modelling of NASA Stage36 based on original blade profile and flow path data is realized and model validation is also conducted. SST $\mathrm{k}-\omega$ turbulence model is employed to study the influence of adding roughness caused by fouling on compressor performance. According to above results, it can conclude that:

Using original blade profile and flow path data, software BladeGen can realize a quick modelling of compressor, which greatly reduces time cost with a high enough accuracy;

Increase of blade roughness will remarkably decrease compressor's total pressure ratio and adiabatic efficiency, with stage characteristic map moving toward left; adding roughness on rotor has a bigger impact than on stator, whereas it cannot neglect the reduction of efficiency caused by roughness on stator under small mass flow situation.

With the same total pressure ratio, an increase of blade surface roughness leads to great increase of input power, and the maximum available input power significantly decreases, which is related to an earlier flow separation caused by surface roughness.

At near-stall point, there is a distinct decrease of the circumferentially averaged relative Mach number of leading edge near $20 \%$ rotor tip when surface roughness adds, meanwhile, Mach number near leading edge of rotor's suction surface increases, and shock wave in the rear position of suction surface moves both forward and far from blade wall.

\section{Acknowledgement}

This work was sponsored by science and technology project of Civil Aviation (20150218), Fundamental Research Funds for the Central Universities (3122016D017) and Tianjin Science and Technology Support Key Project (Grant no. \#15ZCZDGX00350).

\section{References}

1. Nikuradse J. Laws of flow in rough pipes[C]//VDI Forschungsheft. (1933)

2. Schlichting H. Experimentelle untersuchungen zum rauhigkeitsproblem [J].Archive of Applied Mechanics, 7(1): 1-34 (1936)

3. Bammert K, Milsch R. Boundary layers on rough compressor blades[C]//ASME 1972 International Gas Turbine and Fluids Engineering Conference and Products Show. American Society of Mechanical Engineers, (1972), V001T01A047-V001T01A047

4. Syverud E, Brekke O, Bakken L E. Axial compressor deterioration caused bysaltwater ingestion[C]//ASME Turbo Expo 2005: Power for Land, Sea, and Air. American Society of Mechanical Engineers, 327-337 (2005)

5. Syverud E, Bakken L E. The impact of surface roughness on axial compressor performance deterioration[C]//ASME Turbo Expo 2006: Power for Land, Sea, and Air. American Society of Mechanical Engineers, 491-501 (2006)

6. Suder K L, Chima R V, Strazisar A J, et al. The effect of adding roughness and thickness to a transonic axial compressor rotor[C]//ASME 1994 International Gas Turbine and Aeroengine Congress and Exposition. American Society of Mechanical Engineers, (1994), V001T01A113-V001T01A113

7. Morini M, Pinelli M, Spina $P$ R, et al. Computational fluid dynamics simulation of fouling on axial compressor stages[J]. Journal of Engineering for Gas Turbines and Power, 132(7): 072401 (2010)

8. CHEN S, ZHANG C, SHI H, et al. Numerical Study on the Impact of Fouling on Axial Compressor Stages [J]. Journal of Propulsion Technology, 3: 006 (2012)

9. Shi H, Chen SW, Zhang C, et al. Numerical simulation of fouling deposition in compressor rotor[J]. Journal of Aerospace Power, 27(5): 10611067 (2012)

10. Reid L, Moore R D. Design and overall performance of four highly loaded, high speed inlet stages for an advanced high-pressure-ratio core compressor[J]. (1978)

11. ANSYS CFX. Version 14.0[J]. Ansys Inc, (2011) 